\title{
Mutations in G6PC2 do not contribute to monogenic forms of early infancy diabetes and beta cell dysfunction
}

\author{
A. Bonnefond - N. Bouatia-Naji • A. Simon • C. Saint-Martin • A. Dechaume • \\ P. de Lonlay • M. Polak • C. Bellanné-Chantelot • P. Froguel • M. Vaxillaire
}

Received: 7 January 2009/Accepted: 19 January 2009 / Published online: 24 February 2009

(C) Springer-Verlag 2009

Keywords $G 6 P C 2 \cdot$ IGRP · MODY · Mutation screening · Neonatal diabetes mellitus $\cdot$ Pancreatic beta cell .

Persistent hypoglycaemia of infancy

$\begin{array}{ll}\text { Abbreviations } \\ \text { EID } & \text { Early infancy diabetes \# } \\ \text { G6PC } & \text { Glucose-6-phosphatase catalytic subunit } \\ \text { G6PC2 } & \text { Glucose-6-phosphatase catalytic subunit 2 } \\ \text { HI } & \text { Hypoglycaemia of infancy } \\ \text { MODY } & \text { Maturity-onset diabetes of the young } \\ \text { SNP } & \text { Single nucleotide polymorphism } \\ \text { UTR } & \text { Untranslated region }\end{array}$

To the Editor: Monogenic forms of beta cell dysfunction in childhood and young adulthood are rare disorders with genetically heterogeneous aetiologies $[1,2]$. They include neonatal diabetes mellitus ( 1:300,000 newborn infants), maturity onset diabetes of the young (MODY; $\sim 1-2 \%$ of

Electronic supplementary material The online version of this article (doi:10.1007/s00125-009-1299-6) contains supplementary material, which is available to authorised users.

A. Bonnefond $\cdot$ N. Bouatia-Naji $\cdot$ A. Dechaume $\cdot$ P. Froguel $\cdot$

M. Vaxillaire $(\square)$

CNRS 8090-Lille 2 University, Pasteur Institute,

1 rue du Professeur Calmette, BP 245, 59019 Lille, France

e-mail: martine.vaxillaire@good.ibl.fr

A. Simon $\cdot$ M. Polak

Department of Pediatric Endocrinology,

AP-HP Necker-Enfants Malades Hospital,

Paris, France

C. Saint-Martin

Department of Genetics,

AP-HP Groupe Hospitalier Pitié-Salpétrière,

Pierre et Marie Curie-Paris 6 University,

Paris, France non-autoimmune diabetes) and congenital hypoglycaemia of infancy (HI; 1:50,000 newborn infants) [1,2]. At present these disorders are known to involve more than ten genes that are highly expressed in pancreatic beta cells [1-3]. Causal mutations resulting in severely impaired beta cell function and inadequate insulin secretion have been implicated in both early onset diabetes and HI, as has been described for HNF4A (hepatocyte nuclear factor 4, alpha), $G C K$ (glucokinase) or the ATP-sensitive $\mathrm{K}^{+}$channel genes (KCNJ11, ABCC8) [2, 3].

Glucose-6-phosphatase catalytic subunit 2 (G6PC2), also known as islet specific glucose-6-phosphatase related protein (IGRP), is a glycoprotein embedded in the endoplasmic reticulum membrane [4]. G6PC2 belongs to the glucose-6phosphatase family that includes the glucose-6-phosphatase catalytic subunit (G6PC), which catalyses the hydrolysis of glucose 6-phosphate to release endogenous glucose from the gluconeogenic tissues, mainly the liver [5]. The expression of $G 6 P C 2$ is highly specific to pancreatic islets and beta cells

P. de Lonlay · C. Bellanné-Chantelot Metabolic Department and Reference Center for Metabolic Diseases and Inserm U781,

AP-HP Necker-Enfants Malades Hospital, Paris, France

M. Polak

Paris Descartes University and Inserm U845, AP-HP Necker-Enfants Malades Hospital, Paris, France

P. Froguel

Genomic Medicine, Hammersmith Hospital, Imperial College, London, UK 
[6]. Thus, G6PC2 has been proposed to modulate the beta cell glycolytic pathway and glucose-stimulated insulin secretion by antagonising the activity of glucokinase, the major beta cell glucose sensor [6]. Despite 50\% amino acid sequence identity with G6PC, G6PC2 shows little or no enzymatic activity on glucose 6-phosphate hydrolysis [4]. However, we have recently shown that a frequent single nucleotide polymorphism (SNP) within the third intron of G6PC2 is strongly associated with fasting plasma glucose levels and insulin release indices in several independent European populations [6]. Another study independently confirmed our findings and reported several SNPs that had strong effects on fasting plasma glucose levels in the same locus [7]. In a Chinese population, $\mathrm{Hu}$ and colleagues identified a novel $G 6 P C 2$ SNP rs16856187 that confers risk for type 2 diabetes [8]. These genetic findings in humans are consistent with $G 6 p c 2$ invalidation that results in a decrease of approximately $13 \%$ in fasting glucose concentrations in mice [9].

Inactivated heterozygous mutations of $G C K$ that reduce the glucose input into the glycolytic pathway are responsible for MODY type 2; when homozygous, the mutations are responsible for a few cases of permanent neonatal diabetes mellitus. However, gain-of-function mutations that increase glucose metabolism in the beta cell are associated with a persistent phenotype of $\mathrm{HI}$ sensitive to diazoxide [1-3]. In order to evaluate whether gain- or loss-of-function mutations in G6PC2 may be a cause of monogenic forms of beta cell dysfunction in humans, we screened 88 patients for mutations of G6PC2. These patients had genetically unexplained non-autoimmune early infancy diabetes (EID) (either transient $[n=12]$ or permanent $[n=32])$, or MODY $(n=16)$ or the inverse phenotype of congenital HI $(n=28)$ (Table 1). The patients were recruited by the French Network for the Study of Neonatal Diabetes Mellitus, the CNRS-UMR8090 Unit (Lille, France) and the Department of Metabolic Disorders of Necker Hospital (Paris, France). The study was approved by the local ethics committees, and parents provided written informed consent for the genetic testing of their children. Details of the previous genetic testing in these patients are shown in full in Table 1. G6PC2 is located on

Table 1 Clinical characteristics and previous gene screening of patients with unexplained permanent or transient EID, MODY or persistent HI

\begin{tabular}{|c|c|c|c|c|}
\hline Variable & Permanent EID & Transient EID & MODY & Persistent HI \\
\hline$n$ & 32 & 12 & 16 & 28 \\
\hline Sex ratio (male/female) $(n)$ & $18 / 14$ & $5 / 7$ & $11 / 5$ & $15 / 13$ \\
\hline Age at diagnosis $(n)$ & $6(2-15.75)^{\mathrm{a}}$ & $2(1-4.25)^{\mathrm{b}}$ & $20(15.5-22.75)^{\mathrm{c}}$ & $3.75(0-8)^{\mathrm{a}}$ \\
\hline Neonates $(\leq 1$ month of age $)$ & 6 & 10 & 0 & 11 \\
\hline Infants ( 1 month to 18 months of age) & 19 & 2 & 0 & 15 \\
\hline Children (18 months to 6 years old) & 7 & 0 & 1 & 2 \\
\hline \multicolumn{5}{|l|}{ Current treatment $(\%)$} \\
\hline Insulin/OHA/diet/none/not known & $94 / 3 / 0 / 3 / 0$ & $0 / 0 / 17 / 83 / 0$ & $38 / 25 / 6 / 12 / 19$ & - \\
\hline Diazoxide & - & - & - & 100 \\
\hline Birthweight (g) & $3,079 \pm 784$ & $2,018 \pm 652$ & NA & $3,598 \pm 544$ \\
\hline Below 3th percentile $(\%)$ & 15.4 & 66.7 & NA & 0 \\
\hline Below 10th percentile (\%) & 23.1 & 75 & NA & 4.2 \\
\hline Below median $(\%)$ & 73.1 & 100 & NA & 33.3 \\
\hline Above 97th percentile (\%) & 7.7 & 0 & NA & 12.5 \\
\hline \multicolumn{5}{|l|}{ No mutations found $(n)$} \\
\hline$A B C C 8$ & 32 & 12 & 16 & 24 \\
\hline KCNJ11 & 32 & 12 & - & 24 \\
\hline INS & 32 & 12 & 16 & - \\
\hline$G C K^{\mathrm{d}}$ & - & - & 15 & $2^{\mathrm{e}}$ \\
\hline$H N F 1 A$ & - & - & 15 & - \\
\hline No abnormalities in chromosome 6q24 (n) & NA & 12 & NA & NA \\
\hline No autoantibodies associated with type 1 diabetes $(n)$ & 32 & 12 & 16 & NA \\
\hline
\end{tabular}

Data presented as mean \pm SD

Data presented as median age at diagnosis in ${ }^{a}$ months, ${ }^{b}$ days or ${ }^{c}$ years (interquartile range)

${ }^{\mathrm{d}}$ EID patients are now screened for a $G C K$ mutation when both parents are known to have impaired fasting glycaemia or diabetes

${ }^{\mathrm{e}}$ Persistent HI patients with a family history of diabetes or hypoglycaemia (in first or second degree relatives) were screened for $H N F 4 A(n=5)$ or GCK $(n=2)$ mutation, respectively

NA, not applicable 
human chromosome 2q24, and encodes a 355 amino acid protein (MIM\# 608058). The genomic sequences were analysed in 11 fragments spanning the promoter and 5'untranslated regions (UTR) (from nucleotide c.-1100), all five exons, the exon-intron boundaries and the 3'-UTR (up to c.*1921) (primer sequences and PCR conditions are given in Table 1 of the Electronic supplementary material [ESM]). Amplicons were sequenced on a 3730xl DNA Analyser (Applied Biosystems, Foster City, CA, USA) using a standard protocol. Electrophoregram reads were assembled and analysed with the Variant Reporter software (Applied Biosystems).
Analysis of the genomic sequence of G6PC2 revealed 19 rare (minor allele frequency $\leq 0.05$ ) and nine frequent (minor allele frequency $>0.05$ ) variants (Table 2 ). All variants were present in the heterozygous state. They included four exonic and five intronic variants; the other extragenic variants were located in the promoter region and in the 3'-UTR. All four coding variants were located in exon 5 of G6PC2 (Table 2). Three of them were non-synonymous and had been described previously, with an assigned rs number from the dbSNP build 129 database (p.Y207S-rs2232323, p.V219Lrs492594 and p.S342C-rs2232328). The synonymous variant

Table 2 G6PC2 gene variants identified in the patients with unexplained EID, MODY or persistent HI, and control individuals

\begin{tabular}{|c|c|c|c|c|c|c|c|c|c|}
\hline \multirow[t]{2}{*}{ rs number } & \multirow[t]{2}{*}{ SNP } & \multirow{2}{*}{$\begin{array}{l}\text { Position on } \\
\text { chromosome } 2^{a}\end{array}$} & \multirow{2}{*}{$\begin{array}{l}\text { Part of } \\
\text { gene }\end{array}$} & \multicolumn{6}{|c|}{ Minor allele frequency } \\
\hline & & & & $\begin{array}{l}\text { Permanent } \\
\text { EID }(n=32)\end{array}$ & $\begin{array}{l}\text { Transient } \\
\text { EID }(n=12)\end{array}$ & $\begin{array}{l}\text { MODY } \\
(n=16)\end{array}$ & $\begin{array}{l}\text { Persistent HI } \\
(n=28)\end{array}$ & $\begin{array}{l}\text { Controls }{ }^{\mathrm{b}} \\
(n=147)\end{array}$ & $\begin{array}{l}\text { HapMap CEU } \\
\text { population }\end{array}$ \\
\hline rs 540524 & c. $-912 \mathrm{~A}>\mathrm{G}$ & 169.465 .176 & Promoter & 0.33 & 0.25 & 0.47 & 0.32 & 0.28 & 0.30 \\
\hline Novel & c. $-752 \mathrm{C}>\mathrm{T}$ & 169.465 .336 & Promoter & 0 & 0.04 & 0 & 0 & 0 & NA \\
\hline rs2232314 & c. $-713 \mathrm{C}>\mathrm{T}$ & 169.465 .375 & Promoter & 0 & 0 & 0 & 0.02 & 0 & 0 \\
\hline rs1402837 & c. $-488 \mathrm{C}>\mathrm{T}$ & 169.465 .600 & Promoter & 0.14 & 0.29 & 0.22 & 0.20 & 0.21 & 0.30 \\
\hline rs 2232315 & c. $-410 \mathrm{G}>\mathrm{A}$ & 169.465 .678 & Promoter & 0.02 & 0 & 0 & 0 & 0.01 & 0.03 \\
\hline rs573225 & c. $-301 \mathrm{~A}>\mathrm{G}$ & 169.465 .787 & Promoter & 0.33 & 0.46 & 0.28 & 0.30 & 0.42 & 0.33 \\
\hline rs34746523 & c. $-294 \mathrm{~T}>\mathrm{C}$ & 169.465 .794 & Promoter & 0 & 0 & 0.03 & 0 & 0.003 & NA \\
\hline rs2232316 & c. $-280 \mathrm{G}>\mathrm{A}$ & 169.465 .808 & Promoter & 0.22 & 0.08 & 0.09 & 0.16 & 0.11 & 0.10 \\
\hline rs2232318 & c. $220-42 \mathrm{G}>\mathrm{A}$ & 169.467 .159 & Intron 1 & 0 & 0.04 & 0.03 & 0.02 & 0.04 & NA \\
\hline Novel & c. $327+91 \mathrm{G}>\mathrm{C}$ & 169.467 .402 & Intron 2 & 0.02 & 0 & 0 & 0 & 0 & NA \\
\hline rs2232320 & c. $328-147 \mathrm{C}>\mathrm{T}$ & 169.469 .114 & Intron 2 & 0.02 & 0 & 0 & 0.04 & 0.003 & 0 \\
\hline Novel & c. $328-19 \mathrm{G}>\mathrm{A}$ & 169.469 .242 & Intron 2 & 0.03 & 0 & 0 & 0 & 0 & NA \\
\hline rs560887 & c. $439-26 \mathrm{C}>\mathrm{T}$ & 169.471 .394 & Intron 3 & 0.23 & 0.33 & 0.22 & 0.27 & 0.37 & 0.30 \\
\hline rs2232323 & c. $620 \mathrm{~A}>$ C. p.Y207S & 169.472 .387 & Exon 5 & 0.03 & 0.04 & 0 & 0 & 0.01 & 0.025 \\
\hline rs492594 & c. $655 \mathrm{G}>$ C. p.V219L & 169.472 .422 & Exon 5 & 0.55 & 0.38 & 0.56 & 0.48 & 0.37 & 0.37 \\
\hline Novel & c. $699 \mathrm{G}>$ A. p.L233L & 169.472 .466 & Exon 5 & 0 & 0 & 0.03 & 0 & 0 & NA \\
\hline rs 2232328 & c. $1025 \mathrm{C}>$ G. p.S342C & 169.472 .792 & Exon 5 & 0.26 & 0.08 & 0.09 & 0.20 & 0.12 & 0.09 \\
\hline Novel & c. ${ }^{*} 24 \mathrm{~T}>\mathrm{C}$ & 169.472 .859 & 3'UTR & 0.02 & 0 & 0 & 0 & 0 & NA \\
\hline rs2232329 & c. $* 27 \mathrm{G}>\mathrm{A}$ & 169.472 .862 & 3'UTR & 0 & 0 & 0 & 0.02 & 0.01 & NA \\
\hline Novel & c. ${ }^{*} 64 \mathrm{C}>\mathrm{T}$ & 169.472 .899 & 3'UTR & 0.02 & 0 & 0 & 0 & 0 & NA \\
\hline Novel & c. ${ }^{*} 688 \mathrm{~A}>\mathrm{C}$ & 169.473 .523 & 3'UTR & 0 & 0 & 0 & 0.01 & 0.02 & NA \\
\hline rs570876 & c. $* 788 \mathrm{~T}>\mathrm{A}$ & 169.473 .623 & 3'UTR & 0.45 & 0.63 & 0.44 & 0.52 & 0.62 & 0.37 \\
\hline Novel & c. $* 877 \mathrm{G}>\mathrm{A}$ & 169.473 .712 & 3'UTR & 0 & 0 & 0 & 0.04 & 0 & NA \\
\hline rs 567243 & c. $* 1148 \mathrm{~A}>\mathrm{G}$ & 169.473 .983 & 3'UTR & 0.58 & 0.38 & 0.56 & 0.50 & 0.38 & 0.36 \\
\hline Novel & c. $* 1290 \mathrm{~T}>\mathrm{C}$ & 169.474 .125 & 3'UTR & 0.02 & 0 & 0.06 & 0.02 & 0.003 & NA \\
\hline Novel & c. $* 1770 \mathrm{~A}>\mathrm{G}$ & 169.474 .605 & 3'UTR & 0 & 0 & 0.03 & 0 & 0 & NA \\
\hline rs10176348 & c. ${ }^{*} 1774 \mathrm{C}>\mathrm{T}$ & 169.474 .609 & 3'UTR & 0 & 0 & 0 & 0.02 & 0 & 0 \\
\hline Novel & c. ${ }^{*} 1851 \mathrm{~T}>\mathrm{C}$ & 169.474 .686 & 3'UTR & 0 & 0 & 0 & 0.02 & 0 & NA \\
\hline
\end{tabular}

${ }^{a}$ Variant locations are displayed by base numbers counting from the p-arm telomere of chromosome 2 (according to the Base Position feature in the Human (Homo sapiens) Genome Browser Gateway Human Mar. 2006 [hg18] assembly (http://genome.ucsc.edu/cgi-bin/hgGateway, accessed 1 July 2008))

${ }^{\mathrm{b}}$ Control subjects are non-diabetic white individuals including 31 adults (fasting plasma glucose $4.16 \pm 0.22 \mathrm{mmol} / \mathrm{l}$ ) and $116 \mathrm{children}$ (fasting plasma glucose $4.25 \pm 0.29 \mathrm{mmol} / \mathrm{l}$ )

CEU, Centre d'Etude du Polymorphisme (Utah residents with northern and western European ancestry); NA, not available 
(c.699G>A-p.L233L) had not yet been described: it was found in one MODY patient, but was not present in 294 control chromosomes. We investigated the proband's family and observed no obvious segregation between this novel coding variant and diabetes. Ten novel rare (minor allele frequency $<0.05$ ) but non-coding variants were also identified (Table 2). The c. $-752 \mathrm{C}>\mathrm{T}$ variant located in the promoter region was found in one transient EID patient, and was not present in the control group. This sequence variant maps to a non-conserved genomic region across species, according to the UCSC/Penn State Bioinformatics (www.bx.psu.edu/miller_lab/, accessed 1 July 2008). In silico analysis did not predict any transcription factor binding site in the vicinity of c. $-752 \mathrm{C}>\mathrm{T}$ (Genomatix software: www.genomatix.de/, accessed 1 July 2008). Taken together, these data did not support further investigation of the role of c. $-752 \mathrm{C}>\mathrm{T}$ variant. The two new intronic variants (c.327+91G $>\mathrm{C}$ and c.328-147C $>\mathrm{T}$ ) were identified in one and two permanent EID patients respectively, but not in the control group. These intronic variants are located in non-conserved regions across species. Finally, seven novel variants were found in the $3^{\prime}$ UTR (Table 2). No putative microRNA binding sites were predicted in their vicinity according to the TargetScan software (www.targetscan.org/, accessed 1 July 2008).

Our results do not support the notion that G6PC2 disruption may be a common cause of monogenic forms of beta cell dysfunction in humans, at least in our patient cohorts. These findings differ markedly from large epidemiology studies that showed strong associations between common DNA variations at the $G 6 P C 2$ locus and fasting glucose level [6, 7], or even type 2 diabetes in the Chinese population [8]. Such divergent data between the aetiologies of monogenic beta cell disorders and polygenic type 2 diabetes have already been highlighted in previous studies, which did not show that causal mutations in several genes (such as TCF7L2, HHEX or SLC30A8) led to monogenic beta cell dysfunction [10-12], although these gene loci were confirmed to confer risk strongly for type 2 diabetes. Nonetheless, the approach of screening genes known to be involved in polygenic type 2 diabetes for mutations in rare monogenic diabetes has been remarkably fruitful, as exemplified by the pharmacogenetic impact of KCNJ11 mutations [13, 14].

Following our study based on three limited patient cohorts, albeit representative of rare monogenic forms of beta cell dysfunction, it would obviously be informative to test the association between all the novel variants and fasting glucose level or multifactorial forms of type 2 diabetes at the population level. Finally, further molecular studies are still required to clarify the function of G6PC2 in the pancreatic beta cell, particularly with regard to a role in the glucose phosphorylation pathway.
Acknowledgements We thank all patients and their families for participation in the genetic study. We thank H. Cavé and S. Pereira for their long-term collaboration in the establishment of the French neonatal diabetes mellitus cohort, M. Deweirder, F. Allegaert and E. Vaillant for their technical assistance and the management of DNA samples. A. Bonnefond is partly funded by a research fellowship from the Conseil Régional du Nord Pas de Calais (France). N. Bouatia-Naji is supported by a post-doctoral fellowship from the French Agence Nationale de la Recherche (ANR-06 PHYSIO-037-02). This study was supported by the French Agence Nationale de la Recherche (ANR-07-MRAR-NeoDiabGenDev project) and the European Union (Integrated Project EuroDia LSHM-CT-2006-518153 in the Framework Programme 6 [FP6] of the European-Community to P. Froguel).

\section{References}

1. Vaxillaire M, Froguel P (2008) Monogenic diabetes in the young, pharmacogenetics and relevance to multifactorial forms of type 2 diabetes. Endocr Rev 29:254-264

2. Aguilar-Bryan L, Bryan J (2008) Neonatal diabetes mellitus. Endocr Rev 29:265-291

3. Valayannopoulos V, Romano S, Mention K et al (2008) What's new in metabolic and genetic hypoglycaemias: diagnosis and management. Eur J Pediatr 167:257-265

4. Shieh JJ, Pan CJ, Mansfield BC, Chou JY (2005) In islet-specific glucose-6-phosphatase-related protein, the beta cell antigenic sequence that is targeted in diabetes is not responsible for the loss of phosphohydrolase activity. Diabetologia 48:1851-1859

5. Boustead JN, Martin CC, Oeser JK et al (2004) Identification and characterization of a cDNA and the gene encoding the mouse ubiquitously expressed glucose-6-phosphatase catalytic subunitrelated protein. J Mol Endocrinol 32:33-53

6. Bouatia-Naji N, Rocheleau G, Van Lommel L et al (2008) A polymorphism within the G6PC2 gene is associated with fasting plasma glucose levels. Science 320:1085-1088

7. Chen WM, Erdos MR, Jackson AU et al (2008) Variations in the $G 6 P C 2 / A B C B 11$ genomic region are associated with fasting glucose levels. J Clin Invest 118:2620-2628

8. Hu C, Zhang R, Wang C, et al (2009) A genetic variant of G6PC2 is associated with type 2 diabetes and fasting plasma glucose level in the Chinese population. Diabetologia 52:451-456

9. Wang Y, Martin CC, Oeser JK et al (2007) Deletion of the gene encoding the islet-specific glucose-6-phosphatase catalytic subunit-related protein autoantigen results in a mild metabolic phenotype. Diabetologia 50:774-778

10. Cauchi S, Vaxillaire M, Choquet $\mathrm{H}$ et al (2007) No major contribution of TCF7L2 sequence variants to maturity onset of diabetes of the young (MODY) or neonatal diabetes mellitus in French white subjects. Diabetologia 50:214-216

11. Minton JA, van de Bunt M, Boustred C et al (2007) Mutations in HHEX are not a common cause of monogenic forms of beta cell dysfunction. Diabetologia 50:2019-2022

12. Borowiec M, Thompson R, Powers C, Xu R, Dickey T, Doria A (2007) Mutations in the SLC30A8 gene are not a major cause of MODY or other forms of early-onset, autosomal dominant type 2 diabetes. Diabetologia 50:2224-2226

13. Hattersley AT, Ashcroft FM (2005) Activating mutations in Kir6.2 and neonatal diabetes: new clinical syndromes, new scientific insights, and new therapy. Diabetes 54:2503-2513

14. Flechtner I, Vaxillaire M, Cave H, Scharfmann R, Froguel P, Polak M (2007) Diabetes in very young children and mutations in the insulin-secreting cell potassium channel genes: therapeutic consequences. Endocr Dev 12:86-98 